\title{
Protected or Unprotected Sex: The Conceptions and Attitudes of the Youth in Bolgatanga Municipality, Ghana
}

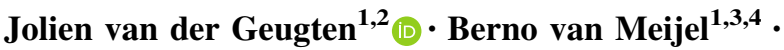 \\ Marion H. G. den $\mathrm{Uyl}^{5}$ • Nanne K. de $\operatorname{Vries}^{2}$
}

(C) The Author(s) 2017. This article is an open access publication

\begin{abstract}
The youth in Bolgatanga municipality in Ghana have relatively less knowledge of sexual and reproductive health (SRH) compared to the youth in other parts of Ghana. More fundamental knowledge is needed of the factors that influence young people to have protected and unprotected sex in specific social and cultural contexts, in order to protect them from adverse consequences, such as sexually transmitted diseases (STIs), HIV/AIDS and unintended pregnancies. This study therefore analyzed the conceptions and attitudes of the youth toward protected and unprotected sex, and particularly condom use, in Bolgatanga municipality. Semistructured and focus group interviews were held with 71 young males and females and 17 adults. The results indicated that many of them lack a comprehensive knowledge of STIs, contraceptives and pregnancy, while a group of them had a negative attitude towards contraceptives. Not all parents, schools and organisations provide young people with a comprehensive education about SRH, and some even discourage such education because they believe it would encourage young people to have sex before marriage. In addition, young people also inform each other about SRH issues, sharing stories and personal experiences with their peers. The information they exchange is not always correct, however; sometimes it merely reflects their own personal preferences. The unequal power in the sexual relationships of
\end{abstract}

Jolien van der Geugten

jolien.vandergeugten@inholland.nl

1 Faculty of Health, Sports and Social Work, Research Centre Mental Health Nursing, Inholland University of Applied Sciences, Amsterdam, The Netherlands

2 Maastricht University Medical Centre+, CAPHRI School for Public Health and Primary Care Maastricht, Maastricht, The Netherlands

3 Parnassia Psychiatric Institute, The Hague, The Netherlands

4 Department of Psychiatry, VU University Medical Center, Amsterdam, The Netherlands

5 Faculty of Social Sciences, VU University Amsterdam, Amsterdam, The Netherlands 
young people-related to the traditional value system that gives men, but not women, "sexual freedom, both in and outside marriage" - is another determining factor for unprotected sex.

Keywords Condom use - Contraceptives · Youth - Sexual transmitted infections · Ghana

\section{Introduction}

The sexually active youth in Ghana are at relative high risk for contracting HIV/ AIDS, other sexually transmitted infections (STIs) and for unintended pregnancies with adverse consequences for their future (Appiah-Agyekum and Suapim 2013; Doyle et al. 2012). Almost three quarters of Ghanaian males and over one-third of Ghanaian females are sexually active before marriage (Ghana Statistical Service, Ghana Health Service and ICF Macro 2009).

Regarding HIV, the national prevalence among adults in Ghana is relatively low (1.5\%) compared to other sub-Saharan African countries such as South Africa (19.2\%) and Zambia (12.9\%) (UNAIDS 2015a, b; Ghana Aids Commission 2014). However, the 15-24 age group accounted for $26 \%$ of the more than 11,000 new infections in 2014; the majority of those infected were female (Ghana Aids Commission 2014). Moreover, Ghana is still considered a high-risk country concerning for various reasons: people lack knowledge of HIV/AIDS and condom use is relatively low (Ghana Aids Commission 2014), people have multiple sexual partners, there are high levels of HIV/AIDS in bordering countries (AppiahAgyekum and Suapim 2013), HIV in Ghana is mostly transmitted through unprotected heterosexual contact (72\%) (Ghana Aids Commission 2014).

Concerning STIs, there is a high incidence of self-reported STIs and STI symptoms (including bad-smelling/abnormal genital discharges and genital sores or ulcers). In 2008, reported by $26 \%$ of females and $8 \%$ of males aged 15-24 (Ghana Statistical Service, Ghana Health Service and ICF Macro 2009). Data on treatmentseeking behaviour among this age group are not available. However, the stigmatization of people with STIs can discourage treatment-seeking. STIs that are not treated can lead to severe complications (WHO 2012).

In additional to HIV/AIDS and STIs, pregnancy among young females has adverse potential consequences for their health and social life, and the society as a whole (Krugu et al. 2016). In 2013, $12 \%$ of Ghanaian females aged 15-19, both married and unmarried, were pregnant. Moreover, in Ghana unsafe abortion is an important cause of morbidity and mortality, particularly among women under 20 years (Sundaram et al. 2012; Abdul-Rahman et al. 2011). It was reported that $16 \%$ of women $(<20$ years) had an abortion in 2007 , while other studies argue that the actual number of unsafe abortions and the attempts could be higher (Ghana Statistical Service, Ghana Health Service and ICF Macro 2009; Mote et al. 2010; Glover et al. 2003).

Most unmarried Ghanaian males and females aged 15-24 reported to have heard of various contraceptive methods (Ghana Statistical Service, Ghana Health Service 
Table 1 Contraceptive use sexually active unmarried females $(15-19$ years $)$

\begin{tabular}{ll}
\hline Contraceptive & Percentage (\%) \\
\hline Male condom & 11 \\
Pill & 5.7 \\
Intrauterine device & 1.5 \\
Injectables & 7.5 \\
Implants & 4.4 \\
Total use & 32 \\
\hline
\end{tabular}

and ICF Macro 2009; Ghana Statistical Service, Ghana Health Service and ICF International 2015). However, a substantial proportion of them lack sufficient knowledge about the use of contraceptives, and use contraceptives inconsistently (Ohene and Akoto 2008). Condom use among sexually active young people is low in Ghana (Ghana Aids Commission 2014; Krugu et al. 2016b). For example, in 2014 , only $32 \%$ of sexually active unmarried females aged 15-19 years used modern contraceptives (see Table 1; Ghana Statistical Service, Ghana Health Service and ICF International 2015).Condom use was reported by less than $40 \%$ of males in 2008 (Doyle et al. 2012). There are various reasons for this, such as their low risk perception, a lack of adequate access, and their concerns about costs and confidentiality (Awusabo-Asare et al. 2006; National Population Council 2011; Bankole et al. 2007; Awusabo-Asare et al. 2004). Additionally, condom use is seen as unnatural and unpleasant, and it may cause distrust in sexual relations (Kuumuori Ganle et al. 2012). It was reported that the higher a woman's education, the more likely she is to ask her partner to use condoms. Rich or middle income women are more likely to ask their partners to use condoms compared to poorer women (Darteh et al. 2014). It is unclear whether transactional sex (i.e., sex for money) affects condom use (Moore et al. 2007). Most churches and religious groups do not promote condoms, because they fear that condom use promotes promiscuity (Appiah-Agyekum and Suapim 2013). It should be remarked that it is not clear if the mentioned studies concerning condom use focus on transmission of HIV/AIDS and other STIs through vaginal intercourse only, or include oral and anal sex as well.

Several scholars have argued that more fundamental knowledge is needed about factors that influence the unprotected and protected sexual behavior of young people, and about the role of these hindering and motivational factors in various social and cultural contexts. This insight could contribute to the development of more tailored and effective sexual and reproductive health (SRH) programs to protect young males and females from the adverse consequences of having sex without contraceptive methods (Darteh et al. 2014; Karim et al. 2003; AwusaboAsare and Annim 2008; Madise et al. 2007).

The youth in Bolgatanga municipality, the capital of the Upper East Region, have relatively less knowledge of SRH, including STIs and HIV/AIDS, compared to the youth in other parts of Ghana, and they have a relatively low level of familiarity with family planning methods (Van der Geugten et al. 2015; Rondini and Kingsley Krugu 2009). A recent study in Bolgatanga municipality reported that $24 \%$ of sexual active junior high school students had used a condom the last time they had 
sex (Krugu et al. 2016b). However, compared to other parts of Ghana, research in this rural, relatively remote northern area is limited.

Abstinence from premarital sex is prescribed for the Frafra (in particular the Gurune) and the Christian and Islamic groups in Bolgatanga municipality, and the virginity of unmarried women is highly valued (Van der Geugten et al. 2013). A considerable number of young males and young females are, however, sexually active before marriage, influenced by increasing modernization, education, and new media (Ghana Statistical Service, Ghana Health Service and ICF Macro 2009; Krugu et al. 2016b; Van der Geugten et al. 2013). In the Upper East Region, the median age of marriage in the region is 24.4 years for males and 18.9 years for females. For females, there is only a slight difference between the median age of first sexual intercourse (18.4) and the median age of marriage (18.9). For males the difference is larger: their median age of first sexual intercourse is 21 and their median age of marriage is 24.4 (Ghana Statistical Service, Ghana Health Service and ICF International 2015).

Quantitative research concerning the sexual behaviour of youth and contraceptive use was done in various parts of Ghana, and recently in Bolgatanga municipality as well (Krugu et al. 2016b; Ghana Statistical Service, Ghana Health Service and ICF International 2015; Ohene and Akoto 2008). However, qualitative research is recommended to gain more fundamental knowledge in specific social and cultural contexts with respect to contraceptive use, STIs (including HIV/AIDS), and unintended pregnancies. Therefore, in the present study, a qualitative method was applied to (1) investigate the conceptions and attitude of the youth toward unprotected and protected premarital sex, in particular condom use, and (2) investigate the sociocultural dynamics and context of using or not using contraceptives as a youth, and the risk of the youth for HIV/AIDS and STIs. The aim is to gain a better understanding of what drives the youth in Bolgatanga municipality in northern Ghana to practice protected or unprotected sex.

\section{Method}

\section{Design}

Semi-structured interviews were carried out with 32 young males and females, and focus group interviews were conducted with a further 39 young males and females. Individual interviews provided a safe setting and privacy for the respondents, while the focus groups motivated respondents to share their ideas and to react to each other. To answer the second research question, not only interviews were held with young males and females, but also with 17 adults who were familiar with the local youth and their problems. These respondents (mostly teachers, social workers, and health workers) provided complementary information about the sociocultural dynamics and context of using or not using contraceptives as a youth, and the risk of the youth for HIV/AIDS and STIs. 


\section{Setting}

Ghana has almost 25 million inhabitants, divided over 10 regions. The three northern regions are the poorest. They are mainly rural and the majority of the people live in villages or small communities. The main source of income is farming. School attendance and literacy rates are low compared to the rest of Ghana (Ghana Statistical Service 2012). Bolgatanga municipality (132,000 inhabitants) is the capital of one of the northern regions. The dominant ethnic group in Bolgatanga municipality is the Gurune (Ghana Statistical Service 2005). The three main religions in Bolgatanga municipality are traditionalism (practised by $22.3 \%$ of the population), Christianity (57.6\%) and Islam (17.1\%). Only $2.7 \%$ have no religious affiliation (Ghana Statistical Service 2014).

The availability of contraceptives in Bolgatanga municipality varies per area. Various brands of male condoms are available at pharmacies, supermarkets, and health clinics, mainly in Bolgatanga town, but also in some of the rural communities. The average price of a condom is US\$ 0.07 (Ghana Statistical Service, Ghana Health Service and ICF Macro 2009). Female condoms were not available in Bolgatanga municipality during data collection. Contraceptive pills and contraceptive injections are available free of charge at government hospitals and clinics upon presentation of a doctor's prescription. Contraceptive pills are also sold at pharmacies (the average price of a month's worth of pills is US\$ 0.09).

\section{Population and Sampling}

The research population comprised young males and females (14-25 years, varying levels of education) and adults (various ages, various background, occupations and religions). For both young people and adults, snowball sampling was done, taking into account gender, age, religion, education, and urbanization. Respondents were approached with the assistance of the Youth Harvest Foundation Ghana (YHFG), churches, mosques, key local figures in the municipality, and the Ghanaian host family of the first author. Respondents were included until data saturation was reached.

\section{Data Collection}

Data were collected in various rounds in the period 2010-2012. In the first stage of the research project (2010-2011), semi-structured interviews that addressed the sexual and relational behavior of the youth were conducted with young people and adults (Van der Geugten et al. 2013). From this first research stage, 12 interviews with 14 young people (two in same-sex pairs) and 17 interviews with adults (six females, 11 males) were selected for the present paper, as they contained the topic "protected or unprotected premarital sex" (see Table 2); a secondary analysis was subsequently applied.

In 2011 and 2012, 16 semi-structured interviews with 18 young males and females (14 individual interviews, two in same-sex pairs) and five focus group interviews with 39 young males and females were conducted (see Table 2). The 
Table 2 Data collection among the youth $(\mathrm{N}=32)$ and adults $(\mathrm{N}=17)$

\begin{tabular}{lll}
\hline & Respondents & Main topic of interview \\
\hline The youth & 71 & - \\
Semi-structured interviews (2010) & 14 & Broad focus on SRH \\
Semi-structured interviews (2011-2012) & 18 & Protected/unprotected sex \\
Focus groups (2011) & 39 & Protected/unprotected sex \\
Adults & & \\
Semi-structured interviews (2010-2011) & 17 & Broad focus on SRH \\
\hline
\end{tabular}

main focus was on unprotected and protected premarital sex and on having multiple sexual partners (the latter issue is addressed in another paper; author). The topic list for the semi-structured and the focus group interviews was based on literature and previous research (Van der Geugten et al. 2013). It contained the following five topics: (1) Prevention of STIs; (2) Opinions, conceptions, and motives concerning condom use; (3) Negotiating space for condom use; (4) Expectations of young males and females concerning condom use; (5) Opinions, conceptions and motives regarding other contraceptive methods. ${ }^{1}$

The order in which the topics were discussed in each interview depended on the answers of the participants. The semi-structured interviews lasted 20-75 min, the focus groups 30-60 min. All interviews were digitally recorded and transcribed verbatim.

Most interviews with the young males and females and adult respondents were conducted by the first author (Dutch woman, familiar with the research area since 2000) and in the English language. Under the supervision of the first author, four interviews with young people were carried out by a female Dutch undergraduate. Three interviews and two focus group interviews with young people were conducted by a male Ghanaian bachelor graduate. He interviewed only young males, and used Gurune (the local language) in four of the five interviews (without an interpreter) in order to allow young males who did not speak English to be included. A local female interpreter (aged 22) assisted in one focus group interview with young females and in 10 semi-structured interviews with young males and females. These interviews were partly in English and partly in Gurune. Both the interpreter and the Ghanaian interviewer were well known by the first author, and had been selected based on their suitability for this task. Of the interviews with the adult respondents, 16 were held in English and one was held in Gurune with the assistance of a local female interpreter (aged 31). Eleven of the 17 interviews with adult respondents were carried out by the first author; two female Dutch undergraduates carried out six interviews, supervised by the first author.

During the various periods of fieldwork, the first author and the Dutch students were hosted by Ghanaian families. This allowed the researchers to experience life in the area and to better understand the social and cultural context.

\footnotetext{
${ }^{1}$ The topic list also included topics concerning multiple sexual partners, which are reported in another paper.
} 


\section{Ethical Approval}

Ethical approval was not needed for this study under Dutch and Ghanaian law during data collection (2010-2012). However, the Ghana Health Service and the Navrongo Health Research Center (NHRC) were officially informed and consulted about the project. The research proposal was also discussed with and approved by the YHFG (partner organization in Bolgatanga providing SRH education to young people) and various local authorities. All interviewed persons were informed about the research objectives by the interviewers, asked to cooperate voluntarily and anonymously, and asked orally for their consent. The majority of those approached agreed to cooperate. Some refused because they were not interested or due to obligations at school, home, or work. Three respondents were aged under 16 years; for one of them permission was also asked and given by her mother, the other two participated in the interviews as part of their attendance in a SRH programme for which permission was given by their parents. Respondents could discontinue their cooperation at any time and personal information was excluded from data analysis and publication.

\section{Data Analysis}

The qualitative data analysis software NVivo 10 was used. As a first step, all interviews were coded with the focus on factors that influence unprotected and protected premarital sex, and particularly condom use. Five categories were defined on the basis of these codes.

The first author carried out the coding in NVivo 10. Methodological aspects of the research, the coding processes (development of codes and categories), and contradictions that were identified during the analysis were documented and systematically discussed by the research group (JvdG, BvM, MdU, NdV). For privacy reasons, respondents were given fictitious names.

\section{Results}

This section presents the demographics of the respondents and elaborates the five categories that were derived from the data to answer the two research questions. These categories-namely (1) the influence of culture and religion, (2) knowledge of contraceptives, STIs, and pregnancy, (3) attitude and behavior regarding buying and possessing condoms, (4) attitude regarding using condoms, and (5) the influence of unequal power relations between young males and females-provide insight into the factors that influence the attitudes toward unprotected and protected premarital sex of the youth in general and condom use in particular.

\section{Demographics}

Semi-structured interviews were held with 32 young people aged 14-25 years. Eighteen were male (mean age 21.4) and 14 were female (mean age 18.9; one was 
pregnant), and they differed in age, religion, ethnicity, and education. All respondents were unmarried. Of the males, 11 were sexually experienced and two were not (for five males this was unknown). Of the females, four were sexually experienced and six were not (for four females this was unknown). Sample characteristics are summarized in Table 3.

In addition, 39 young people participated in five focus group interviews. Three focus group interviews were held with 22 young males aged 16-25 years (mean age 21.8). Although the age range was announced when selecting the young respondents, three unmarried men aged 29, 30, and 32 years, respectively, were also present. Because the interview had already started when they mentioned their ages, it was thought that it would disturb the group if they were sent away. They were therefore included in the research. One of the focus groups with young males was held in a rural area; participants were either school dropouts, attending junior high school, cowherds, or farmers. The other two focus groups with young males were held in urban areas; most of these participants were attending senior high school (SHS). Two focus groups were conducted with 14 young females aged 16-21 years (mean age 18.1). One was held in a rural area, with six young females who were either school dropouts or attending junior high school (JHS). The other focus group was held with eight young females, all of whom were attending a boarding SHS. The majority of the respondents in all focus groups were Christian; the others were Muslim or Traditionalist.

Six female and 11 male adults were also interviewed; their ages, religions, and backgrounds varied. Sample characteristics are summarized in Table 4.

\section{The Influence of Culture and Religion}

In three focus groups, and in four interviews with young females, the respondents spoke about the traditional and religious ideology of abstinence from premarital sex, particularly in relation to the prevention of STIs and pregnancies. It was explained that abstinence is an important way to avoid unprotected sex and its adverse consequences. For example, Gifty (18, SHS student, Christian) said that she believes that, as a virgin, she will not only get the right partner and the respect of the community, but also be protected from STIs and unintended pregnancy. One male (focus group urban area) also said: "But those who prevent it, to have sex, they prevent sickness and at the same time pregnancy."

It is tradition among the Frafra in Bolgatanga municipality for fathers to talk to their sons, and for mothers to talk to their daughters, about puberty and its physical changes, abstinence from premarital sex, and the duties of a husband or wife. These talks are initiated the moment a child undergoes physical changes related to physical maturity (e.g., menarche or pubic hair growth). Most uneducated parents still give these traditional talks, but they often do not have enough knowledge of SRH and the risks involved for their children, according to Patrick (social worker) and Sayida (community nurse). In Patrick's words:

The other category of parents are the illiterate parents who have no exposure to anything of development and new things of our world, our developing 
Table 3 Demographics of the participating youth in the semistructured interviews $(\mathrm{n}=32)$

\begin{tabular}{|c|c|c|}
\hline & \multicolumn{2}{|l|}{$\overline{\text { Sex }}$} \\
\hline & Male & $18(56 \%)$ \\
\hline & Female & $14(44 \%)$ \\
\hline tructured interviews $(n=32)$ & \multicolumn{2}{|l|}{ Age } \\
\hline & Males [mean (range)] & $21.4(19-25)$ \\
\hline & Females [mean (range)] & $18.9(14-23)$ \\
\hline & \multicolumn{2}{|l|}{ Ethnicity } \\
\hline & Frafra & $23(72 \%)$ \\
\hline & Other (Hausa, Bakasan, Dagomba) & $3(9 \%)$ \\
\hline & Unknown & $6(19 \%)$ \\
\hline & \multicolumn{2}{|l|}{ Urbanization } \\
\hline & Bolgatanga municipality & $29(91 \%)$ \\
\hline & Rural community & $15(47 \%)$ \\
\hline & Bolgatanga town & $4(13 \%)$ \\
\hline & Not specified & $10(31 \%)$ \\
\hline & Bongo District $^{\mathrm{a}}$ & $3(9 \%)$ \\
\hline & \multicolumn{2}{|l|}{ Education } \\
\hline & Not educated & $3(9 \%)$ \\
\hline & School drop-out JHS ${ }^{\mathrm{b}}$ & $1(3 \%)$ \\
\hline & Attending JHS & $2(6 \%)$ \\
\hline & Completed JHS & $2(6 \%)$ \\
\hline & Completed vocational school & $1(3 \%)$ \\
\hline & Attending $\mathrm{SHS}^{\mathrm{c}}$ & $8(25 \%)$ \\
\hline & Completed SHS & $10(31 \%)$ \\
\hline & Attending polytechnic & $1(3 \%)$ \\
\hline & Attending/completed university & $2(6 \%)$ \\
\hline & Unknown & $2(6 \%)$ \\
\hline & \multicolumn{2}{|l|}{ Religion } \\
\hline & Christian & $18(56 \%)$ \\
\hline & Muslim & $7(22 \%)$ \\
\hline & Traditionalist & $5(16 \%)$ \\
\hline & Unknown & $2(6 \%)$ \\
\hline & \multicolumn{2}{|l|}{ Sexual experienced } \\
\hline & \multicolumn{2}{|l|}{ Males } \\
\hline & Yes & $11(61 \%)$ \\
\hline & No & $2(11 \%)$ \\
\hline & Unknown & $5(28 \%)$ \\
\hline & \multicolumn{2}{|l|}{ Females } \\
\hline & Yes & $4(29 \%)$ \\
\hline a Schooling in Bolgatanga & No & $6(43 \%)$ \\
\hline $\begin{array}{l}\text { municipality; }{ }^{\mathrm{b}} J H S \text { junior high } \\
\text { school; }{ }^{\mathrm{c}} \text { SHS senior high school }\end{array}$ & Unknown & $4(29 \%)$ \\
\hline
\end{tabular}

Number (\%)

Males [mean (range)]

Ethnicity

Frafra

$3(72 \%)$

(91\%)

$(47 \%)$

$(31 \%)$

Education

$(3 \%)$

$(6 \%)$

(3\%)

$(31 \%)$

$1(3 \%)$

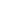


Table 4 Demographics of the participating adults in the semistructured interviews $(\mathrm{n}=17)$

\begin{tabular}{llc} 
Table 4 Demographics of the & & Number (\%) \\
participating adults in the semi- & & \\
\cline { 2 - 3 } structured interviews $(\mathrm{n}=17)$ & Sex & $11(65)$ \\
& Male & $6(35)$ \\
& Female & \\
& Age & $6(35)$ \\
& $26-35$ years & $7(41)$ \\
& $36-55$ years & $4(24)$ \\
& $56-64$ years & \\
& Ethnicity & $10(59)$ \\
& Frafra & $1(6)$ \\
& Moshi & $1(6)$ \\
& Kassena & $1(6)$ \\
& Dagao & $4(24)$ \\
& Unknown & \\
in church, traditional leader & Religion & $13(77)$ \\
& Christian & $3(18)$ \\
& Muslim & $1(6)$
\end{tabular}

1 Youth pastor, youth president in church, traditional leader

world. (...) In my work, especially in the north, I have seen that there are these illiterate parents, who are waiting and still going by the informal way of preparing young people, you know, to face marital life.

A few young people said that their parents had warned them that unprotected sex can have unintended and unwanted consequences. However, Sayida (community nurse) said that only a relatively small proportion of the educated parents actually talk about SRH to their children, while others send them to the health clinic for SRH education. Apart from the parents' knowledge of SRH, talking about SRH-related issues to young people is still a cultural taboo, according to Patrick (social worker), Sayida (community nurse), John (teacher), and Felix (parent). It is seen as immoral and it is feared that it could encourage young people to have sex. Sayida and Ruth (social worker) taught young people about condom use, and were consequently accused of encouraging immoral behavior. Sayida remarked: 
People sometimes confront me personally, telling me that: "I'm spoiling the youths. Why should I talk about condoms? They should stay away from sex." Which is not real, they can't, they can't stay away from sex. They are doing it!

In the interviews, Islamic and Christian leaders said that in the church and the mosque they continue to promote abstinence to the youth and discourage condom use. Patrick (social worker) stated that some of the Christian youth ignored the advice of church leaders and used condoms - some did so secretly-to protect themselves against HIV in particular. George (21, Christian, completed SHS) said that he engaged in premarital sex and advocated condom use: "So if they cannot abstain, then it will be very good for them to use the condom, because you know the abstinence is very difficult for them to do that."

Some of the adults said that parents have a responsibility for the attitude and behavior of the youth regarding unprotected premarital sex, and their knowledge or lack thereof of STIs, contraceptives, and pregnancy. For example, Sayida (community nurse) said: "So it's high time we come out openly to talk to our children about sex and about condoms, because they are becoming pregnant." Felix (parent) confirmed the taboo on talking about sex, but also said that the traditional ideas are losing ground:

Because we think that sex is secret! Sex should not be mentioned. For example, if I talk about penis, they say I'm immoral. (...) So in Africa, that is the problem. But it's, we are overcoming it. It's changing fast.

Furthermore, the way parents and children communicate has changed because of increasing modernity, according to one young male and one young female and various adults: Young people nowadays do not obey their parents, they go to friends rather than their parents with their problems, and "they do what they want." Felicity (teacher) said that parents found it difficult to control their children. Francis (25, uneducated farmer) said:

The problem with us the youths of these days is the influence from our own peers. It is our friends. For instance, a young boy or girl may have a problem and instead of talking it out with his or her mother or father so that they can give them good advice on how to solve that problem, they would rather talk it out with their friends who most often all they can give is bad advice.

It was noticed, however, that in general it was not common in the Frafra tradition for parents and children to converse extensively, or for children to approach their parents with questions. Sayida (community nurse) said: "Really, do you see a man and a woman and the children conversing? No, in our tradition, when grownups are there, children don't go near there." Mohammed (parent and Islamic leader) commented that most parents are ignorant about their children's sexual and relational behavior, and do not know whether they use family planning methods. He also said-as did George (21, Christian, completed SHS, sexually experienced) and Joyce (15, Christian, SHS student, not sexually experienced)-that the youth hide their sexual and relational activities from their parents. Joyce: 
But the parents will never know. It's when the pregnancy comes, that you run to your parents. That's the only time they will know that your child is having a boyfriend. Because no parent will support that [having a boyfriend]. Unless you are maybe at the age of marriage.

Moreover, Ruth (social worker) and John (teacher) said that that it would be better if parents were to talk with their children, they "can do a lot." Ruth said that she wishes parents would make time and create opportunities for their children to share their problems with them.

\section{Knowledge of Contraceptives, STIs, and Pregnancy}

The lack of knowledge of a considerable number of respondents about contraceptives, STIs, and pregnancy came to the fore as a factor that influences the protected or unprotected premarital sexual behavior of the youth, and particularly their condom use. The consequences of unprotected sex, and how STIs (including HIV) are transmitted, were not well known among the youth, according to two young males and two young females. For example, Ayine (21, completed SHS, Traditionalist) said: “They [youths] are ignorant because they don't know the consequences of having unsafe sex. They just go ahead and go on to have sex without." Abdul (21, SHS student, Muslim) gave the following statement, which he claimed to have learned from a teacher: "So, if only the girl has HIV/AIDS and she doesn't have a cut, it's not easy for her to give you HIV/AIDS."

Regarding contraceptives, most respondents knew where to buy male condoms in Bolgatanga municipality, such as pharmacies, supermarkets, and health clinics. However, not all respondents seemed sure about the safety and usage of contraceptives. For instance, Caroline (18, completed JHS, Traditionalist) asked during the interview: "They always say a condom is not $100 \%$ safe. Is it true?"

Several respondents, in a focus group and in the individual interviews, also doubted the safety of male condoms: They wondered whether condoms could burst and whether they could be punctured. It was mentioned in the focus group with female SHS students that the female condom is not safe either. The female SHS students in the focus group and two young females in the individual interviews also expressed concerns that contraceptive pills and injections could cause infertility. Insufficient knowledge was also found with respect to pregnancy prevention. To prevent pregnancies, some young people practice the withdrawal method and some of the young females keep track of their "safe" days within their menstruation cycle, without knowing the risks of these methods. In the focus group with the female SHS students, one student said that they could have unprotected sex as long as the young males say that they will not ejaculate inside them. Joyce (15, SHS student, Christian) said about unprotected sex during "safe" days: "Maybe, they will say, well I just had my menses. They think that, oh, I had my menses some time ago, so I don't think if I do it right now I'll get pregnant."

During the interviews, most young people showed interest in learning more about $\mathrm{SRH}$, the risks associated with unprotected sex, and the use of contraceptives. Ayine (21, completed SHS, Traditionalist) said that education might "help" the youth to 
have protected sex. Particularly education in how to use condoms was mentioned by some of the respondents. One female participant (Christian) in the focus group in a rural area said that "We need to be educated in how to use condoms, which is very important to us," and Clement (20, completed SHS, Christian) said "Even when you learn that condom is the best way to prevent it, you can go and buy the condom. Yet you don't know how to do it, and it will be useless."

Sayida (community nurse) confirmed that young people lack knowledge of SRH, and that more females than males come to her with questions and problems regarding STIs and pregnancy.

\section{Attitude and Behavior Regarding Buying and Possessing Condoms}

The attitude and behavior of the youth regarding buying and possessing condoms appears to influence their protected or unprotected premarital sexual behavior, and particularly their use of condoms. A small proportion of the males did not have a problem with going into a shop and buying condoms. George (21, sexually experienced) said: "So I always feel free, I have one drug store that I always buy, so even sometimes when I get there and I place the money on the table, he knows what I want."

Three young females also said that they would feel comfortable about buying condoms; one of them confirmed she actually bought condoms. Diana (23, Christian, apprentice seamstress):

Me like this, I don't have fear of anything, if I want to, if I'm, my boyfriend, I will always, I will let him know that me I will do it. Because he did not marry me yet. And you know boys, they go out and they come in, they go out and they get different, different ladies, ahaa. So it's only good.

Most young males and females, however, said that they felt uncomfortable about buying condoms. One female SHS student said in a focus group:

I think due to that too, like the shyness, I may not go and buy it myself. So, I will say, maybe I feel shy to go to the drugstore and tell the person that I want condom or something like that.

Some of the young males also experienced this barrier. Hashim (23, completed SHS, Muslim, sexually experienced):

Personally me like this, I feel so shy that I feel heavy to go there to buy a condom (...). You see that like the traditional teaching in Bolga here, is that already sex before marriage is a crime. We see it as something that is odd.(...) It is rampant. It is everywhere but still the elders see it (...) It is a bad behavior.

In the focus group with female SHS students and in the interview with Hashim, it was said that young people could also ask a younger person (it is culturally accepted to assign younger persons, especially younger siblings), or an older brother or friend, to buy condoms for them if they themselves felt too shy to go. Sophia (22) 
and Claudia (14) mentioned the use of different names to hide their order for a condom such as "cd," "doncom," and "this thing."

Although most young males and females said they felt uncomfortable about buying and possessing condoms, this feeling seemed to be stronger in females than in males. This difference in attitude was brought up in both focus groups with young females, and in the interviews with four young females and two young males (various religions, aged 14-23 years). According to them, buying and possessing condoms can lead to remarks such as "bad girl," "bad boy," or "you are too young," and that young females would be seen as prostitutes. Ruth (social worker) also said that, in general, it was socially more acceptable and easier for males to buy and possess condoms compared to females. Regarding the possession of condoms, some young males and females said that parents do not allow their sons or their daughters to possess condoms, because they should abstain from premarital sex.

\section{Attitude Toward the Use of Condoms}

Another factor that influences whether young people have protected or unprotected premarital sex, is their attitude toward the actual use of condoms. Almost half of the young females and three of the young males (14-23 years, various religions, all educated) said that it is important to protect oneself against STIs and pregnancies by using a condom. Rudolf (24, Traditionalist, completed SHS, sexually experienced) said that it is important to have a condom available: "It's not difficult, so far there is any time that you come into my room, I will make sure the condom is always available before having the sex. Don't do it without condom."

Albert (20, Christian, completed SHS, sexually experienced) also explained that his future, and in particular his education, motivates him to use condoms:

But to me, I believe in using condoms because, you know (...) it's better like, to keep your feelings okay. But I believe in my future more than in sex, so for me going to the high level is better than to have sex and maybe contract any diseases.

However, according to the majority of the respondents (various ages, religions, and educational backgrounds), not all young males and females want to use condoms. In a focus group with young males in an urban area, one participant said:

Some boys prevent it through using condoms, but some boys don't prevent. They don't even prefer using condom. When you ask them why, they say "Oh, when they use the condom they don't feel." They don't feel like making love.

Gregory (24, completed SHS, rural area, sexually experienced) said the following about what young males and females feel about using condoms:

Yes, because there are some girls or some boys, that if they are using the condom to have the sex, they don't feel like, they don't feel the percentage they are supposed to, like you see, using a condom to have sex with, or using without condom, the percentage is always different. It's different (...) there is much feeling if you use without condom, and there is less feeling if you use 
with condom. So that's why some boys and there are some girls that if you even use condom with them they won't like.

Saïda (23, completed SHS, Muslim, rural area, sexually experienced) made a negative statement about condom use: "Some too are there with the decision that they don't want to use it. Simply because they always say they feel when they use it for sex, they don't really enjoy much of the sex." However, George (21, Christian, completed SHS, SRH peer educator, sexually experienced) held a different opinion: "It's the same thing, whether condom or not, it's the same feelings, it's the same, what will happen will still happen." He also said that there are girls who do not like the use of condoms because they can cause heat friction in their vaginas.

One of the social workers (26, female, Christian), who was also an SRH educator, remarked that most young people preferred not to use condoms:

So if you tell them that, put the condom on before you have sex. They are, like, when you buy a toffee, do you just put it in your mouth like that? (...) So you see they are trying to tell us that, if you put a candy in your mouth like that you don't, uhmm, you don't feel the taste immediately, you have to chew it or something when you come. When they use condom, they don't get satisfied, or they don't get the feeling. So they prefer to go the natural way. They call it the raw way.

It was noted that peers, especially same-sex peers, have an important role in advising and influencing each other regarding SRH. Although most young people said that sexual intercourse with a condom gives less pleasure and less "feeling" than without a condom, most of them did not talk about their own experience, but about what they had heard from their peers. For example, Thomas (21, Christian, completed SHS, not sexual experienced):

I have enough experience from my friends. That when you use protection with girls it's like you don't feel. You don't feel. (...) Even though sometimes they tell me but I've never been in their shoes before. I've never done such thing. So I believe them. 'Cause they have been doing it.

In two interviews and one focus group with young females, it was said that males sometimes cut off half or the top of the condom, without their partners realizing it, in order to "have more feeling." One female SHS student (Christian) said in the focus group: "Sometimes they will pretend to use it, meanwhile they will remove it. They can intentionally cut half of it."

Mutual trust between boyfriend and girlfriend is an important factor that influences the use of condoms, according to three young males and one young female. When young people trust each other they do not use protection, and in the case of distrust, they like to use a condom. Suggesting using a condom could therefore make a partner suspicious: The one suggesting it might have an STI and not admit it. David (20, Christian, university student) said that young people are afraid their partner would break up the relationship if they were honest about having an STI. In the focus group with the female SHS students, it was mentioned that young males want their first sexual intercourse to be "raw" (without a condom): 
"Because the first time they have sex with you, they want to do that so that you know that you are getting to like him or not."

Additionally, Francis (25, uneducated farmer) said that it is important to find out soon whether you are "sexually compatible": "It is very necessary for you to try her fast and see how she tastes."

Deciding to use condoms after being tested positive for HIV or another STI was mentioned in a focus group with young males in a rural area, and by three young males and two young females in individual interviews. However, none of them reported having actually had such a blood test.

\section{Unequal Power Relations Between Boys and Girls}

It was found that unequal power in sexual relationships between young males and females is also important when it comes to the actual use of condoms. Three young females said that if males insisted on not using a condom, females could not force them to do so. Saïda (23, completed SHS, Muslim, rural area) pointed out that young males are physically stronger than young females:

It's not easy, if the guy doesn't want it, I don't think you can find it easy using it. Because you cannot force him. And mostly the guys have the power over the ladies, that they can force them to do what they want, but you a lady, simply because our strength is not equal.

Another reason given for agreeing to have sex without a condom, is the girl's love for her boyfriend. Samira (21, SHS student, Muslim, rural area): "If the boy says 'I don't like using condom,' and then the girl too thinks that she loves the boy, you see that she will just give herself to him. Without a condom."

A female youth's financial dependence on her boyfriend might also contribute to unprotected sex. According to three young males and three young females and some of the adults, some of the young females in the research area have transactional, unprotected sex with young males in order to provide for their needs. It allows them to buy the food, clothes, and luxury items that their parents are too poor to provide. Some of the young females were encouraged by their female friends to engage in these transactional sexual relationships, despite the health risks. Caroline (18, completed JHS, Traditionalist) said:

Yes, because when you are about two, three or four girls going, you see that one of the girls can go into a boy, that is giving her much money, or plenty money. And the fellow [girl] can influence you that you also go and friend this guy, he's having money, he also gives you the money. Not knowing that that guy is having these diseases. And you too go into that guy, and he gives you money. After giving you the money he also wants to get something from you.

Condom use was seen as the males' responsibility, according to one young male and two young females. They said that young males are mostly in charge of buying condoms and having them handy, that they should initiate condom use, and that they are the ones who have to wear the condom. Lydia $(>20$, completed university, Christian) said: "It's like the guy always uses the condom so they [young females] 
don't really have much to say about that." Rudolf (24, Traditionalist, completed SHS) said:

And then the selling of condoms is now open to any place, you can go to any shop and then you get the condom to buy. (...) Yeah they normally, mostly it's the boys' one that is common in our community here.

However, not all girls accepted the unequal power relation between males and females. One sexually experienced female youth said that the use of condoms was her responsibility (17, JHS student, Traditionalist, rural area). She said that she would insist on condom use, even if the boy did not agree: "Yes, if he will not agree then I will stop it, I will say I will not do it. And he cannot force you to do it."

\section{Discussion}

This study focused on conceptions and attitudes of the youth toward protected and unprotected premarital sex, and in particular condom use, in Bolgatanga municipality, Ghana. Various reasons and motivations for these sexual practices were identified: (1) the influence of culture and religion, (2) knowledge of contraceptives, STIs, and pregnancy, (3) attitudes and behavior regarding buying and possessing condoms, (4) attitudes regarding using condoms, and (5) the unequal power relations between young males and females.

Young peoples' lack of comprehensive knowledge of STIs, contraceptives, and pregnancy, as well as their ambivalent and inconsistent attitude regarding condoms and other contraceptives, is probably rooted in the taboo on premarital sexuality, which is related to the strong promotion of premarital sexual abstinence by the Traditionalist, Christian, and Islamic religions in the research area. Not all parents, schools, churches, mosques, and organizations educate young people comprehensively about SRH, and some even discourage SRH education because they fear it would encourage young people to have sex. Parents' reluctance to teach their children about SRH and limited communication between parents and children were both observed in the present study.

Moreover, it was noticed that parents themselves had a lack of knowledge regarding SRH. It was also found that there is a gap between traditional cultural and religious values on the one hand, and increasing modernity and education on the other hand, which creates a distance between parents and children. The growing influence of Christianity and Islam, which promote abstinence from premarital sex, strengthens the conviction held by parents that premarital sex education is unnecessary. The norms to abstain from premarital sex and the taboo on educating young people about SRH were easy to maintain in the past, when young people mostly remained within their communities until they were married. Nowadays, most young people have more independent and autonomous lives: They visit their friends in other communities, use the internet on smart phones, and go to school or to work.

In order to have a more effective policy regarding premarital sexual behavior, parents, as well as schools and religious organizations, need to adjust to these developments. This requires a different approach, one that may require parents, 
teachers, and other key figures to increase their knowledge regarding: (1) Sexual and reproductive health and rights in general and particularly contraceptives; (2) the positive effects of early SRH education; (3) places where young people can obtain SRH education or consult an SRH professional; and (4) the adverse consequences of unprotected sex. They might also have to improve their skills in discussing SRHrelated issues with young people. Research in other sub-Saharan African countries has shown that communication about SRH between children and parents is not common (Biddlecom et al. 2009), and that programs can help parents to improve this communication, which has positive effects on the adolescents' health (WHO 2007).

As stated, national Ghanaian data show that $11 \%$ of unmarried sexual active girls used condoms in 2014, and that less than $40 \%$ of boys aged 15-19 used condoms in 2008 (Ghana Statistical Service, Ghana Health Service and ICF International 2015; Doyle et al. 2012). A recent study among junior high school students in Bolgatanga (Krugu et al. 2016b). We recommend the execution of more quantitative research on this topic. It is a promising finding in the current study that almost half of the girls and some of the boys had a positive attitude toward using male condoms to prevent STIs and pregnancy. However, the majority were uncomfortable about buying and possessing condoms, which might be related to the cultural and religious taboo on premarital sex.

Other contraceptives - such as pills, injections, and female condoms-were hardly used or mentioned by respondents in the present study. Moreover, the safety of these other contraceptives was questioned by some of the girls, who feared they can cause infertility. Concerns of infertility when using contraceptives were also found among women in Accra (Hindin et al. 2014). It is worrisome that young people still do not have easy access to contraceptives, or feel uncomfortable about obtaining or using them, particularly since the Ghanaian government has been promoting condom use for more than 10 years now, and research as long ago as 1997 showed that the Ghanaian youth feel embarrassed about buying and carrying condoms (Awusabo-Asare et al. 2004).

It was found that same-sex peers play an important role with respect to the SRH of the youth in Bolgatanga municipality: Most of the young respondents in this study did not talk about their personal experience with condoms, but mainly about what they had heard from their peers. Peers generally share stories and inform each other about SRH issues, but the "facts" they communicate are not always correct or are merely personal preferences. The fact that most of the youth do not talk about their personal experience can be attributed to various factors, for example, their lack of sexual experience, the cultural and religious taboo, or their personal shyness related to this taboo. In order to improve SRH education, it is important to include the influence of peers in SRH education, particularly because tales of unpleasant experiences with contraceptives spread rapidly among peers, which was also found in a small study in Accra, the Ghanaian capital (AppiahAgyekum and Kayi 2013).

The use of condoms might cause suspicion and distrust between sexually active young people, because it might lead them to doubt each other's faithfulness. This suspicion might also be influenced by the "ABC" strategy that the Ghanaian 
government has been promoting for over a decade: If one cannot abstain (A) from sex or be faithful (B), then use condoms (C). Using a condom might thus imply that one has other sex partners as well. The prevalence of polygyny in Bolgatanga municipality (in 2011, it was practiced by $25 \%$ of men and $39 \%$ of women (Ghana Statistical Service 2012) might also contribute to distrust: The acceptance of polygyny coupled with the unlimited sexual freedom of Ghanaian men inside and outside marriage (Anarfi and Owusu 2011), means there will always be suspicion among women, even when their partners declare that they are faithful.

The unequal power balance in premarital sexual relationships between young males and females - which comes to the fore in explanations about physical strength, being helplessly in love, or female financial dependence-also plays a role in whether young people have protected or unprotected sex. It was said that because males are physically stronger, it is difficult for females to insist on condom use. Moreover, condoms were mostly seen as the responsibility of males: The condom is a "male" prophylactic, and it is embedded in a culture in which males have more authority than females.

The findings that young males and females have limited knowledge of SRH and contraceptives, and that condom use is seen as unpleasant and might cause distrust in sexual relationships, are in accordance with previous research in other subSaharan countries and northern parts of Ghana (Kuumuori Ganle et al. 2012; Rondini and Kingsley Krugu 2009; Sayles et al. 2006). The qualitative interviews with young people and adults in the present study — which revealed young peoples' feelings, fears, shyness, and dilemmas regarding protected and unprotected sex, condom use, and premarital sexual abstinence — contribute to a better understanding of their premarital sexual behavior. Understanding the influencing factors that motivate young males and females to have protected or unprotected sex, and understanding these factors in specific contexts, can contribute to the development of more tailored and effective SRH education to protect young people from the adverse consequences of engaging in unprotected sex (Darteh et al. 2014; Karim et al. 2003; Madise et al. 2007).

\section{Strengths and Limitations}

A strength of this study is that young people in a remote region in northern Ghana shared their perceptions of sexual relationships, something that has rarely been done before. Another strength is that qualitative research was used, which provides indepth insights into and information about the research topic. Additionally, using three interviewers increased the credibility of the results. Two Dutch females interviewed both males and females, and they were looked upon as "outsiders" who would leave again. This ensured the privacy of the respondents, which is particularly important for young females, who are supposed to be virgins. One Ghanaian male interviewed only young males, in order to decrease possible bias caused by only females interviewing young males. The validity of this study was increased by using two data collection methods: individual and focus group interviews. Addressing personal topics in a focus group interview could be a limitation, particularly when respondents do not feel confident in a group. In this 
study, it was experienced that young people were motivated to react on each other and shared their point of view. Although the individual interviews gained more indepth stories of respondents, the focus group interviews were relevant complementary data.

This study also had its limitations. The results might have been influenced by the fact that the study included among the young males and females more older respondents $(\geq 18)$ than younger respondents $(\leq 17)$, and relatively more Christians than Muslims and Traditionalists. Further, data on religion and ethnicity were missing for some of the respondents. Finally, an interpreter was used in some of the interviews, which could have influenced the conversation, and for practical reasons, member checks (respondents checking the interview transcripts) could not be done.

\section{Implications}

In the development and delivery of SRH programs, it should be taken into account that the traditional and religious ideas concerning premarital sex contradict the modern, western-oriented ideas in Bolgatanga municipality. Both streams of ideas influence the knowledge of contraceptives, STIs, and pregnancy of the youth, which turns out to be limited and sometimes also incoherent. Although the attitudes of young people toward the use of male condoms to prevent STIs and pregnancy are in general positive, there are various reasons why they do not use them consistently. SRH education should address the misinterpretations regarding the safety and side effects of contraceptives, as well as how to deal with distrust in sexual relationships and how to handle the stories told by their peers. Additionally, young males and females should be enabled to access contraceptives easily and without feeling uncomfortable or stigmatized.

It is important to involve parents and other key figures in SRH education. The traditional family role of preparing young people for marriage and informing them about SRH issues needs to change now that an increased number of young males and females have more autonomous lives, go to school, and have premarital sex. For instance, teachers, religious leaders, and health and social workers could promote the healthy sexual and reproductive development of young people by providing comprehensive SRH education or counseling. Additionally, the increased use of the internet on smart phones by young people could contribute to improve their knowledge of SRH, but only when they are taught how and where to find reliable information.

\section{Compliance with Ethical Standards}

Conflict of interest All authors declare that they have no conflict of interest.

Ethical Approval All procedures performed in studies involving human participants were in accordance with the ethical standards of the institutional and/or national research committee and with the 1964 Helsinki declaration and its later amendments or comparable ethical standards. 
Informed Consent Informed consent was obtained orally from all individual participants included in the study.

Open Access This article is distributed under the terms of the Creative Commons Attribution 4.0 International License (http://creativecommons.org/licenses/by/4.0/), which permits unrestricted use, distribution, and reproduction in any medium, provided you give appropriate credit to the original author(s) and the source, provide a link to the Creative Commons license, and indicate if changes were made.

\section{References}

Abdul-Rahman, L., Marrone, G., \& Johansson, A. (2011). Trends in contraceptive use among female adolescents in Ghana. African Journal of Reproductive Health, 15(2), 45-55.

Anarfi, J. K., \& Owusu, A. Y. (2011). The making of a sexual being in Ghana: The state, religion and the influence of society as agents of sexual socialization. Sexuality and Culture, 15, 1-18.

Appiah-Agyekum, N. N., \& Kayi, E. A. (2013). Students' perceptions of contraceptives in university of Ghana. Journal of Family and Reproductive Health, 7(1), 39-44.

Appiah-Agyekum, N. N., \& Suapim, R. H. (2013). Knowledge and awareness of HIV/AIDS among high school girls in Ghana. HIV/AIDS-Research and Palliative Care, 5, 137-144.

Awusabo-Asare, K., Abane, A. M., \& Kumi-Kyereme, K. (2004). Adolescent sexual and reproductive health in Ghana: A synthesis of research evidence. New York: The Alan Guttmacher Institute.

Awusabo-Asare, K., \& Annim, S. K. (2008). Wealth status and risky sexual behaviour in Ghana and Kenya. Applied Health Economics and Health Policy, 6(1), 27-39.

Awusabo-Asare, K., Biddlecom, A., Kumi-Kyereme, A., \& Patterson, K. (2006). Adolescent sexual and reproductive health in Ghana: Results from the 2004 national survey of adolescents (Vol. 22). New York: Guttmacher Institute.

Bankole, A., Ahmed, F. H., Neema, S., Ouedraogo, C., \& Konyani, S. (2007). Knowledge of correct condom use and consistency of use among adolescents in four countries in Sub-Saharan Africa. African Journal of Reproductive Health, 11(3), 197-220.

Biddlecom, A., Awusabo-Asare, K., \& Bankole, A. (2009). Role of parents in adolescent sexual activity and contraceptive use in four African countries. International Perspectives on Sexual and Reproductive Health, 35(2), 72-81.

Darteh, E. K. M., Doku, D. T., \& Esia-Donkoh, K. (2014). Reproductive health decision making among Ghanaian women. Reprod Health, 11, 23.

Doyle, A. M., Mavedzenge, S. N., Plummer, M. L., \& Ross, D. A. (2012). The sexual behaviour of adolescents in sub-Saharan Africa: Patterns and trends from national surveys. Tropical Medicine \& International Health, 17(7), 796-807.

Ghana Aids Commission (GAC). (2014). 2014 Status report. Accra: Ghana Aids Commission.

Ghana Statistical Service (GSS). (2005). 2000 Population and housing. Census analysis of district data and implications for planning Upper East Region. Accra: Ghana Statistical Service.

Ghana Statistical Service (GSS). (2012). Ghana multiple indicator cluster survey with enhanced malariamodule and biomarker, 2011, final report. Accra: Ghana Statistical Service.

Ghana Statistical Service (GSS). (2014). 2010 Population and housing census. District analytical report. Bolgatanga municipality. Bolgatanga: Ghana Statistical Service.

Ghana Statistical Service (GSS), Ghana Health Service (GHS), \& ICF International. (2015). Ghana Demographic and Health Survey 2014. Rockville, MD: GSS, GHS, and ICF International.

Ghana Statistical Service (GSS), Ghana Health Service (GHS), \& ICF Macro. (2009). Ghana demographic and health survey 2008. Calverton, MD: Ghana Statistical Service; Noguchi Memorial Institute for Medical Research (NMIMR); ORC Macro.

Glover, E. K., Bannerman, A., Pence, B. W., Jones, H., Miller, R., Weiss, E., et al. (2003). Sexual health experiences of adolescents in three Ghanaian towns. International Family Planning Perspectives, 29(1), 32-40.

Hindin, M. J., McGough, L. J., \& Adanu, R. M. (2014). Misperceptions, misinformation and myths about modern contraceptive use in Ghana. Journal of Family Planning \& Reproductive Health Care, $40(1), 30-35$. 
Karim, A. M., Magnani, R. J., Morgan, G. T., \& Bond, K. C. (2003). Reproductive health risk and protective factors among unmarried youth in Ghana. International Family Planning Perspectives, 29(1), 1424.

Krugu, J. K., Mevissen, F. E. F., Debpuur, C., \& Ruiter, R. A. C. (2016a). Psychosocial correlates of condom use intentions among junior high school students in the Bolgatanga municipality of Ghana. International Journal of Sexual Health, 28(1), 96-110.

Krugu, J. K., Mevissen, F. E. F., Prinsen, A., \& Ruiter, R. A. C. (2016b). Who's that girl? A qualitative analysis of adolescent girls' views on factors associated with teenage pregnancies in Bolgatanga, Ghana. Reprod Health, 13, 39.

Kuumuori Ganle, J., Tagoe-Darko, E., \& Mensah, C. M. (2012). Youth, HIV/AIDS risks and sexuality in contemporary Ghana: Examining the gap between awareness and behaviour change. International Journal of Humanities and Social Science, 2(21), 88-99.

Madise, N., Zulu, E., \& Ciera, J. (2007). Is poverty a driver for risky sexual behaviour? Evidence from national surveys of adolescents in four African countries. African Journal of Reproductive Health, 11(3), 83-98.

Moore, A. M., Biddlecom, A. E., \& Zulu, E. M. (2007). Prevalence and meanings of exchange of money or gifts for sex in unmarried adolescent sexual relationships in Sub-Saharan Africa. African Journal of Reproductive Health, 11(3), 44-61.

Mote, C. V., Otupiri, E., \& Hindin, M. J. (2010). Factors associated with induced abortion among women in Hohoe. Ghana. African Journal of Reproductive Health, 14(4), 115-122.

National Population Council. (2011). Ghana population stabilisation report. Ghana: National Population Council.

Ohene, S., \& Akoto, I. O. (2008). Factors associated with sexual transmitted infections among young Ghanaian women. Ghana Medical Journal, 42(3), 96-100.

Rondini, S., \& Kingsley Krugu, J. (2009). Knowledge, attitude and practices study on reproductive health among secondary school students in Bolgatanga, upper east region, Ghana. African Journal of Reproductive Health, 13(4), 51-66.

Sayles, J. N., Pettifor, A., Wong, M. D., MacPhail, C., Lee, S., Hendriksen, E., et al. (2006). Factors associated with self-efficacy for condom use and sexual negotiation among South African youth. Journal of Acquired Immune Deficiency Syndromes, 43(2), 226-233.

Sundaram, A., Juarez, F., Bankole, A., \& Singh, S. (2012). Factors associated with abortion-seeking and obtaining a safe abortion in Ghana. Studies in Familyplanning, 43(4), 273-286.

UNAIDS. (2015a). HIV and AIDS estimates. Retrieved from http://www.unaids.org/en/regionscountries/ countries/southafrica

UNAIDS. (2015b). HIV and AIDS estimates. Retrieved from http://www.unaids.org/en/regionscountries/ countries/zambia

Van Der Geugten, J., Van Meijel, B., Den Uyl, M., \& De Vries, N. K. (2013). Virginity, sex, money and desire: Premarital sexual behaviour of youths in Bolgatanga municipality, Ghana. African Journal of Reproductive Health, 17(4), 93-106.

Van der Geugten, J., Van Meijel, B., Den Uyl, M. H. G., \& De Vries, N. K. (2015). Evaluation of a sexual and reproductive health education programme: Students' knowledge, attitude and behaviour in Bolgatanga municipality, northern Ghana. African Journal of Reproductive Health, 19(3), 126-136.

World Health Organization. (2007). Summaries of project in developing countries assisting the parents of adolescents. Geneva: World Health Organization.

World Health Organization. (2012). Global incidence and prevalence of selected curable sexually transmitted infections-2008. Geneva: World Health Organization. 